\title{
When to start anticonvulsant treatment in childhood epilepsy: the case for avoiding or delaying treatment
}

\author{
D Mellor
}

Lastly we may observe, to the great comfort and satisfaction of the parents of those children subject to convulsions, or the epilepsia infantilis, that they need not be apprehensive of its changing into the true epilepsy, for it generally disappears by degrees, as they grow older and acquire more strength.

As a young doctor I held the fairly simplistic and conventional view that patients with epilepsy need to start long term treatment with anticonvulsant drugs as soon as the diagnosis is clear. I accepted that epilepsy could not be diagnosed after a single seizure but believed that treatment was necessary if a recurrence happened within a year.

These views were first challenged for me by a middle class couple in whose six year old daughter idiopathic grand mal epilepsy had been diagnosed after she had had three short seizures over four months. After getting me to agree that anticonvulsant drugs did not always work and were not without potential side effects they asked me to spell out the benefits from preventing further seizures. My four answers seemed a little lame to them and to me that $(a)$ a seizure without warning may cause physical injury - for example, a fall into a fire or in front of a motor vehicle- $(b)$ there is a slight risk of status epilepticus, which if prolonged may cause brain damage, (c) seizures are socially embarrassing, and $(d)$ there is a widely held belief that early treatment of epilepsy improves the chances of "growing out of it."

For a risk-benefit analysis of early long term anticonvulsant treatment my last answer seemed the most important but the evidence was poor. Are things any clearer now? What is the evidence that early treatment of epilepsy with anticonvulsant drugs prevents some children from developing chronic intractable epilepsy?

\section{Does early treatment improve prognosis?}

Studies of groups of patients with epilepsy in referral clinics based in hospitals show that rates of remission are better in patients referred early for treatment than in those referred late. ${ }^{2}$ The conclusion from these data that early treatment improves the rate of remission should be resisted. Proportionately more patients with longstanding intractable epilepsy may be being referred to such clinics than patients with a short history of a few seizures and a good prognosis. Even in community based studies of the prognosis of epilepsy patients with severe epilepsy are more likely to be enrolled than those with two or three seizures, especially if the seizures occur at long intervals. Only by randomising entrants prospectively to early or delayed anticonvulsant treatment will reliable answers to this important question be found. Such a study has yet to be done.

Most patients with epilepsy go into remission after a period of active epilepsy. Annegers et al identified all newly diagnosed epileptic patients in Rochester, Minnesota, from 1935 to $1974 .^{3}$ Of those followed up for 20 years, as many as $65 \%$ were in a remission that had lasted at least five years. Roughly half of them had successfully stopped treatment.

Although prolonged seizures, especially febrile ones, may cause brain damage and secondary intractable epilepsy, most children with recurrent short seizures are not at great risk of developing status epilepticus. General acknowledgement of the importance of controlling prolonged seizures and the advent of intravenous diazepam for use in hospitals and rectal diazepam for administration by parents have made this risk extremely small.

\section{Is kindling a relevant model?}

An experimental animal model of epilepsy known as kindling has been held by some to be an important mechanism in the development of human epilepsy. Repeated subconvulsive electrical stimuli are given to an animal's brain and after a variable period of time seizures occur with each stimulus. After this stage seizures occur spontaneously and become intractable. Kindling, however, has never been shown in humans. Indeed, the more "encephalised" the brain the more difficult it is to kindle-for example, a rat's brain can be kindled more easily than a monkey's.

Studies of the prognosis of childhood epilepsy do not give support for this theoretical model. All paediatricians have known children with severe epilepsy who have gone on to complete remission. Thurston et al reported a 15-23 year follow up study of 148 children with epilepsy whose anticonvulsant treatment was

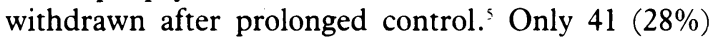
had a recurrence of seizures. Moreover, when the severity of epilepsy was categorised according to the total number of seizures before control was achieved by anticonvulsant drugs no significant relation was found with the rate of relapse (table).

Analysis of patients with temporal lobe epilepsy treated by temporal lobectomy has shown that the

\section{EDITORIAL COMMENT}

The main therapeutic issue in childhood epilepsy is whether treatment with drugs will improve the quality of life for the child concerned. Anticonvulsant drugs are likely to prevent further seizures, but for most children doctors are still reduced to gazing into crystal balls in deciding whether seizures will recur. If treatment were to reduce the risk of lasting cerebral damage or to make a remission more likely or more speedy the scales would tip towards drug treatment. On the other hand, if the use of anticonvulsant drugs in childhood led to abnormalities of cognitive or behavioural development the scale would tip away.
Regrettably, studies that would enable us to balance the risks against the benefits have not been done. The article by Dr Verity highlights in a useful, practical way certain groups in whom the decision to treat is comparatively easy. Dr Mellor's article adds a proper word of caution, which is particularly relevant to most cases of childhood epilepsy likely to be seen in the community. In the final analysis the decision whether to use anticonvulsant treatment will be heavily influenced by both parental attitudes and the lifestyle of the child concerned.

Drs Verity and Mellor have asked me to point out that they have polarised their views for the purposes of this article.-PETER RUBIN, professor of therapeutics, University Hospital, Nottingham NG7 $2 U H$ 
Controversies in

\section{Therapeutics}

longer the interval between the first seizure and surgery, the less favourable the clinical result. ${ }^{6}$

Relapse rate after withdrawal of anticonvulsants related to total number of seizures before control by anticonvulsant treatment

\begin{tabular}{lcccc}
\hline & $\begin{array}{l}\text { Total No of seizures before } \\
\text { control by anticonvulsants }\end{array}$ \\
\cline { 2 - 4 } & $3-5$ & $6-12$ & $>12$ \\
\hline Relapse after withdrawal of anticonvulsants (\%) & 27 & 32 & 28
\end{tabular}

Kindling of the hippocampus and amygdala by the irritative temporal lobe focus has been a suggested explanation for this observation. There is, however, an equally tenable but more mundane interpretation; cases of short duration temporal lobe epilepsy have a better prognosis than those of long duration whether or not they come to operation.

\section{Treatment considerations}

Long term treatment with anticonvulsant drugs carries well known risks of idiosyncratic and dose related side effects, some of which may be life threatening such as Stevens-Johnson syndrome, blood dyscrasias, and liver failure. Little is known of the permanent effects of these drugs on the developing nervous system, but many are recognised as being able to produce subtle cognitive and behavioural changes in some children even when blood concentrations are maintained within the so called therapeutic range. No completely safe anticonvulsant drug is known or is likely to be developed. Children should not be given long term anticonvulsant treatment unless the benefits clearly outweigh the risks.
Parents of children who have had febrile convulsions should be instructed in managing fever and giving rectal diazepam if required. The overall prognosis for febrile convulsions is excellent. ${ }^{7}$ Only $2 \%$ develop epilepsy with non-febrile seizures, although recurrence with one or more febrile convulsions occurs in $35 \%$. Even in children with prolonged, recurrent, or other complicated febrile convulsions the risk of subsequent epilepsy is only $4 \%$.

There is no indication for starting long term anticonvulsant treatment after a single afebrile convulsive seizure. Hauser $e t$ al found that the cumulative risk of recurrence was only $18 \%$ at one year, $21 \%$ at two years, and $27 \%$ at three years. ${ }^{8}$ If the seizure is prolonged, however, the parents should be taught how to give rectal diazepam. In the case of recurrent afebrile seizures many factors come into the decision, including the type of epileptic seizure and parental attitudes. In general, however, long term anticonvulsant treatment should be delayed until it becomes clear that there are no signs of spontaneous resolution and that the continuing seizures are adversely affecting the child's life. In so doing some children will avoid ever having to start long term treatment.

1 Von Rosenstein. Diseases of children and their remedies. British ed, 1766. Quoted by Brett EM. Paediatric neurology. Edinburgh: Churchill Livingstone, 1983:275.

2 Rodin EA. The prognosis of patients with epilepsy. Springfield, Illinois: Charles C Thomas, 1968.

3 Annegers JF, Hauser WA, Elverback LR. Remission of seizure and relapse in patients with epilepsy. Epilepsia 1979;20:729-37.

4 Glaser GH. Kindling. Dev Med Child Neurol 1983:25:376-80.

5 Thurston JH, Thurston DL, Hixon BB, Keller AJ. Prognosis of childhood epilepsy: additional follow-up of 148 childten 15 to 23 years after withdrawal epilepsy: additional follow-up of 148 childten 15 to 23 yea

$6 \mathrm{Glaser} \mathrm{GH}$. Treatment of intractable temporal lobe-limbic epilepsy (complex partial seizures) by temporal lobectomy. Ann Neurol 1980;8:455-9.

partial seizures, by temporal lobectomy. Ann Neurol $1980 ; 8: 455-9$.
Nelson KB, Ellenberg JH. Predictors of epilepsy in children who have Nelson KB, Ellenberg JH. Predictors of epilepsy in children
experienced febrile convulsions. N Engl f Med 1976;295:1029-33.

8 Hauser WA, Anderson VE, Loewenson RB, McRoberts SM. Seizure recurrence after a first unprovoked seizure. $N$ Engl F Med 1982;307:522-8

\section{M Verity \\ continued from page 1528}

treated seizures. ${ }^{15}$ Their results are relevant to a discussion about treating children. They obtained evidence that early suppression of seizures improved the subsequent prognosis: the longer the seizures continued after the start of treatment the less likely they were to go into remission; a high pretreatment frequency of tonic-clonic seizures indicated a worse prognosis; and in patients who had two or more tonic-clonic attacks before the start of treatment the interval between attacks tended to become shorter. Thus an escalating process seems to be found and should be arrested as soon as possible. Reynolds found that rates of remission were lower in patients with neuropsychiatric handicap, cerebral pathology, or partial (rather than tonic-clonic) seizures. The presence of one or more of these factors might be an indication for earlier treatment.

Single seizures-Should people be treated after a first seizure? Several reviews have pointed out that the question is difficult to answer..$^{15-17}$ One of the reasons is that there is disagreement about the prognosis: $27 \%$ of patients had a recurrence after three years in one study, $80 \%$ in another. ${ }^{15}$ There is general agreement on one point: no adequate investigation of the problem has been carried out.

\section{Conclusion}

Severe seizures can undoubtedly cause neurological damage. The difficulty is in knowing how actively to treat short or infrequent attacks. Evidence shows that early treatment may arrest an escalating process in patients with seizures and that some high risk groups are at particular risk of recurrence. A policy of early treatment might save more patients from chronic epilepsy.

I thank Dr Janice Anderson, for supplying the diagram and the photomicrograph.

: Gowers WR. Epilepsy and other chronic convulsive diseases. London: Churchill Livingstone, 1881.

2 Aicardi J, Chevrie JJ. Convulsive status epilepticus in infants and children. A study of 239 cases. Epilepsia 1970;11:187-97.

3 Meldrum BS. Secondary pathology of febrile and experimental convulsions. In: Brazier MAB, Coceani $\mathrm{F}$, eds. Brain dysfunction in infantile febrile In: Brazier MAB, Coceani F, eds. Brain
convulsions. New York: Raven, 1976:213-22.

4 Falconer MA. Surgical treatment of sequelae of severe febrile convulsions. In: Brazier MAB, Coceani F, eds. Brain dysfunction in infantile febrile convulsions. New York: Raven, 1976:307-26.

5 Goddard GV. Development of epileptic seizures through brain stimulation at low intensity. Nature 1967;214:1020-1.

6 Aicardi J, Chevrie JJ. Febrile convulsions: neurological sequelae and mental retardation. In: Brazier MAB, Coceani F, eds. Brain dysfunction in infantile febrile convulsions. New York: Raven, 1976:247-57.

7 Nelson KB, Ellenberg JH. Predictors of epilepsy in children who have experienced febrile seizures. $N$ Engl f Med 1976;295:1029-33.

8 Ellenberg JH, Nelson KB. Febrile seizures and later intellectual performance. Arch Neurol 1978;35:17-21.

9 Verity CM, Butler NR, Golding J. Febrile convulsions in a national cohort followed up from birth. I. Prevalence and recurrence in the first five years of life. Br Med J 1985;290:1307-10.

10 Annegers JF, Hauser WA, Shirts SB, Kurland LT. Factors prognostic of unprovoked seizures after febrile convulsions. $N$ Engl $f$ Med 1987;316: unprov

11 National Institutes of Health. Febrile seizures: long-term management of children with fever-associated seizures. Summary of an NIH consensus statement. Br Med f 1980;281:277-9.

12 Anonymous. The management of febrile convulsions. Drug Ther Bull 1987;25 9-11.

13 Gordon N. Epilepsy-to treat or not to treat. Pediatric Rev Commun 1987;1:163-80.

14 Wallace SJ. The child with febrile seizures. London: John Wright, 1988.

15 Reynolds EH. The initiation of anticonvulsant drug therapy: implications for prognosis. In: Pedley TA, Meldrum BS, eds. Recent advances in epilepsy. No 2. London: Churchill Livingstone, 1985:101-9.

16 Hauser WA. Should people be treated after a first seizure? Arch Neurol 1986;43:1287-8.

17 Shorvon S. When should anticonvulsant treatment be started? In: Ross E, Chadwick D, Crawford R, eds. Epilepsy in young people. Chichester: Wiley, 1987:53-63. 